\title{
Factors Associated with Larval Control Practices in a Dengue Outbreak Prone Area
}

\author{
Mariam Mohamad, Mohamad Ikhsan Selamat, and Zaliha Ismail \\ Faculty of Medicine, Universiti Teknologi MARA, Jln Hospital, Sungai Buloh Campus, 47000 Sungai Buloh, Selangor, Malaysia \\ Correspondence should be addressed to Mariam Mohamad; mariammd@salam.uitm.edu.my
}

Received 9 June 2014; Accepted 8 September 2014; Published 17 September 2014

Academic Editor: Pam R. Factor-Litvak

Copyright ( 2014 Mariam Mohamad et al. This is an open access article distributed under the Creative Commons Attribution License, which permits unrestricted use, distribution, and reproduction in any medium, provided the original work is properly cited.

\begin{abstract}
In order to reduce the risk of dengue outbreak recurrence in a dengue outbreak prone area, the members of the community need to sustain certain behavior to prevent mosquito from breeding. Our study aims to identify the factors associated with larval control practices in this particular community. A cross-sectional study involves 322 respondents living in a dengue outbreak prone area who were interviewed using a pretested questionnaire. The level of knowledge about Aedes mosquitoes, dengue transmission, its symptoms, and personal preventive measures ranges from fair to good. The level of attitude towards preventive measures was high. However, reported level of personal larval control practices was low (33.2\%). Our multiple logistic regression analysis showed that only those with a good level of attitude towards personal preventive measure and frequent attendance to health campaigns were significantly associated with the good larval control practices. We conclude that, in a dengue outbreak prone area, having a good attitude towards preventive measures and frequent participation in health campaigns are important factors to sustain practices on larval control.
\end{abstract}

\section{Introduction}

Almost $50 \%$ of the world's population is living in dengue infection risk areas, a mosquitoes-borne fever with 50-100 million cases reported annually and about $2.5 \%$ affected died [1]. Aedes mosquitoes particularly Ae. aegypti and Ae. albopictus are two known vectors that play the crucial role of transmitting dengue virus from an infected host (mainly human) to another human being. To date, the main measures for vector control include destroying the mosquitoes' larval breeding sites either by chemical, biological, or environmental management and space spraying using insecticides to kill the adult mosquitoes [2]. Both of these measures need collaboration from the community as well as the public health authorities. Thus, evidences to support local community participation to destroy the mosquitoes are essential.

Malaysia is a highly endemic country for dengue infection, which experienced 3- to 5-year cycles of outbreaks [3]. In 2013, the incidences of dengue and dengue haemorrhagic fever were 143.3 and 2.6 per 100,000 populations, respectively, with mortality rate of 0.31 per 100,000 [4]. The control program is highly subsidized by the government and the bulk of the prevention and control measures are done by the public health authority [5]. Localities are monitored by number of dengue cases reported and are considered as having outbreak when there is more than one case of dengue occurring within 14 days from the date of onset of the first case. These areas would then undergo intensive measures (standard operating procedure) for dengue outbreak control. Apart from adulticiding by space spray and using insecticide, antidengue campaigns which include community participation in the activities of mass cleaning of the area, health education activities, for example, talks, exhibition, and distribution of health education materials regarding dengue infection and control measures are also carried out. As for larval control practices, the residents are educated on how to identify and destroy breeding areas and the use of larvacides (chemical or biological). These practices required the people living in the community particularly those living in the highly endemic or outbreak prone area to practice and sustain the behavior in order to reduce the incidence of dengue infection that could be fatal to them. 
Our study aims to find out the level and factors that are associated with the practice of larval control among the residents who live in a dengue outbreak prone area. We hope that we would be able to identify the sustenance factor for the behavior in this particular group of high risk community.

\section{Material and Methods}

A community based cross-sectional study was carried out in an apartment type living area in Selangor, Malaysia. The area was a known dengue outbreak prone area, defined as an area which recently (within a year) had a dengue outbreak episode. The area had been subjected to many dengue control activities in accordance with the national guideline which includes antidengue campaign before our study was done.

We calculated the estimated sample size of 320 respondents based on 95\% confidence level, 5\% precision with prevalence proportion (level of good larval control practices) of $25 \%$, and a nonresponse rate of $10 \%$ using the single proportion formula $[6,7]$.

The study area consists of 10 blocks of 6-storey low cost apartment, where each floor consists of 10 units of living quarters, giving a total of 600 living quarters. The occupancy rate was approximately $60 \%$ which gives rise to 360 occupied living quarters. We conducted cluster sampling using occupied living quarters as the cluster and the head of all occupied living quarters as our respondents. If the head of the household was not available after the second visit, the oldest person in the house was selected to be the respondent.

Respondents were interviewed using pretested questionnaire by trained interviewers. Verbal consent was gathered before the interview after the objective of the study was informed to the respondent. The questionnaire contained 4 sections. Section 1 covers the sociodemographic details and Section 2 contained questions on knowledge regarding Aedes mosquitoes identification and behavior (7 questions), dengue transmission (9 questions), dengue symptoms (20 questions), and prevention measures (7 questions). Section 3 was on attitude towards larval control practices (8 questions) while Section 4 was on self-reported frequency of participation in antidengue campaign held in the area and frequency of carrying out larval control practice (4 questions) using 5point frequency scale. There were four questions related to larval control practices, that is, the frequency of eliminating containers with stagnant water surrounding their home, frequency of covering water containers at home, frequency of cleaning water containers at home, and lastly frequency of putting ABATE (or larvicides) in a water filled container in their home.

Data were entered and analyzed using IBM SPSS Statistics 20. After descriptive analysis, the frequency of larval control practices was then categorized into two groups, that is, poor practice (those with a total score of 15 and below) and good practice (score of 16 and above) and was treated as the dependent variable in our inferential analysis. Simple logistic regression analysis was done to determine the important independent variables for larval control practice; the variables with $P$ value of $<0.25$ were selected to be included in the multiple logistic regressions. Those with $P$ value of $<0.05$ were considered as statistically significant. Multicolinearity, interaction, and model fit analyses were also done to the model.

Our study was approved by the Research and Ethics Committee of Universiti Teknologi MARA.

\section{Results}

Out of 360 living quarters identified, 322 respondents from each living quarter were interviewed (89.4\%). The nonresponse was either because there were no people in the house after two visits or people refused to participate.

The mean age of our respondents was 33.9 years (SD 11.0) with a range between 15 and 65 years old and mean monthly household income of RM 2252 (SD 1258). More than half $(54.3 \%)$ were females and majority attained secondary and tertiary education $(88.2 \%)$ and are married (72.4\%). About $10.6 \%$ of the respondents had been diagnosed as having dengue infection before. About $52.8 \%$ of our respondents perceived themselves as having high risk for dengue infection (Table 1).

The mean score for knowledge regarding Aedes mosquitoes was $5.69 \pm 1.28$ over 7.00 , knowledge about dengue transmission was $4.59 \pm 1.93$ over 8.00 , knowledge about dengue symptoms was $12.03 \pm 4.00$ over 20 , and knowledge of personal preventive measures was $5.52 \pm 1.49$ over 7.00 (Table 2). All the means of the four knowledge scopes were between fair and good level.

As for attitude towards personal preventive measures, the mean score was considerably good, that is, $32.50 \pm 5.87$ over 40 .

About $75 \%$ of our respondents never use bed nets and $40 \%$ never use mosquito coils, while nearly $15 \%$ never use mosquitoes aerosol. As for the larval control practice, those who reported never destroying or eliminating containers with stagnant water inside, surrounding their home were $7.5 \%$, never covering water container at home were $11.5 \%$, never cleaning the water container at home were $8.1 \%$, and, lastly, never using larvicide (ABATE) in a water filled container in their home were $36.6 \%$. Using these four questions, we later categorized them into two groups, that is, poor practice (those with a total score of 15 and below) and good practice (score of 16 and above).

Our simple logistic regression analysis shows that being unemployed and housewife and having more knowledge on Aedes mosquitoes, on dengue symptoms, and on personal preventive measures together with a better attitude towards personal preventive measures, always or most of the time joining dengue campaign, were the significant associated factors for good larval control practices (Table 3).

In our multiple logistic regression analysis, it was found that having better attitude towards personal preventive measures $(P=0.004$; adjusted OR $1.08(1.02,1.14))$ and always or most of the time joining campaigns (adjusted OR 3.83 (1.96, 7.50)) were significant (Table 4). 
TABLE 1: Sociodemographic characteristics of the respondent $(n=$ $322)$.

\begin{tabular}{|c|c|c|c|c|}
\hline & Frequency & $\%$ & Mean & SD \\
\hline Mean age (years) & & & 33.9 & 11.0 \\
\hline $\begin{array}{l}\text { Mean household income per } \\
\text { month }(\mathrm{RM})(n=257)\end{array}$ & & & 2252 & 1258 \\
\hline $\begin{array}{l}\text { Mean number of people in } \\
\text { household }\end{array}$ & & & 4.8 & 1.9 \\
\hline \multicolumn{5}{|l|}{ Sex } \\
\hline Male & 147 & 45.7 & & \\
\hline Female & 175 & 54.3 & & \\
\hline \multicolumn{5}{|l|}{ Highest education level } \\
\hline No formal and primary & 38 & 11.8 & & \\
\hline $\begin{array}{l}\text { Secondary and tertiary } \\
\text { education }\end{array}$ & 284 & 88.2 & & \\
\hline \multicolumn{5}{|l|}{ Current employment status } \\
\hline Employed & 161 & 50.0 & & \\
\hline Unemployed and housewife & 120 & 37.3 & & \\
\hline Student & 36 & 11.2 & & \\
\hline Pensioner & 5 & 1.6 & & \\
\hline \multicolumn{5}{|l|}{ Marital status } \\
\hline Married & 233 & 72.4 & & \\
\hline Single/divorced/separated & 89 & 27.6 & & \\
\hline \multicolumn{5}{|l|}{ Citizenship } \\
\hline Malaysian & 309 & 96.0 & & \\
\hline Non-Malaysian & 13 & 4.0 & & \\
\hline \multicolumn{5}{|l|}{ Ethnic group } \\
\hline Malay & 257 & 79.8 & & \\
\hline Non-Malay & 65 & 20.2 & & \\
\hline \multicolumn{5}{|l|}{ Risk perception } \\
\hline Strongly disagree & 28 & 8.7 & & \\
\hline Disagree & 61 & 18.9 & & \\
\hline Neutral & 63 & 19.6 & & \\
\hline Agree & 120 & 37.3 & & \\
\hline Strongly agree & 50 & 15.5 & & \\
\hline \multicolumn{5}{|l|}{$\begin{array}{l}\text { Ever diagnosed as having dengue } \\
\text { infection }(n=321)\end{array}$} \\
\hline Yes & 34 & 10.6 & & \\
\hline No/Do not know & 287 & 89.1 & & \\
\hline Grand total & 322 & & & \\
\hline
\end{tabular}

\section{Discussion}

Our study found that in a dengue outbreak prone area, the level of knowledge among the residents on Aedes mosquitoes, dengue transmission, its symptoms, and personal preventive measures ranges from fair to good. Even attitude towards preventive measures was high. However, the ultimate target to have a frequent level of personal practices of larval control was low (33.2\%). Although there is no "standard" level to measure adequacy or acceptable level for this particular behavior or practices, we consider $33 \%$ as low. A study in periurban areas in Laos reported larval breeding control
TABLE 2: Mean knowledge score and percentage of respondents reported personal adult mosquitoes control and larval control practices.

\begin{tabular}{lcccc}
\hline & Frequency & $\%$ & Mean & SD \\
\hline $\begin{array}{l}\text { Knowledge on Aedes } \\
\text { mosquitoes (score 0 to 7) }\end{array}$ & & & 5.69 & 1.28 \\
Knowledge on dengue & & & 4.59 & 1.93 \\
transmission (score 0 to 8) & & & & \\
Knowledge of dengue & & & 12.03 & 4.00 \\
symptoms (score 0 to 20) & & & & \\
Knowledge on personal & & & 5.52 & 1.49 \\
preventive measures (score 0 to & & & & \\
7) & & & & \\
Attitude towards personal & & & 32.50 & 5.87 \\
preventive measures (score 8 to & & & & \\
40) & & & & \\
Use of mosquitoes aerosol & & & & \\
$\quad$ Never & 47 & 14.6 & & \\
$\quad$ Few or sometimes & 154 & 47.8 & & \\
$\quad$ Most of the time and always & 121 & 37.6 & & \\
Use mosquitoes coils & & & & \\
$\quad$ Never & 128 & 39.8 & & \\
$\quad$ Few or sometimes & 119 & 37.0 & & \\
$\quad$ Most of the time and always & 75 & 23.3 & & \\
Use bed nets & & & & \\
$\quad$ Never & 240 & 74.5 & & \\
$\quad$ Few or sometimes & 52 & 16.1 & & \\
$\quad$ Most of the time and always & 30 & 9.3 & & \\
Join the campaign & & & & \\
$\quad$ Never & & & & \\
$\quad$ Few or sometimes & & & & \\
$\quad$ Most of the time and always & 61 & 107.9 & & \\
control of practice of larval & & & & \\
\hline
\end{tabular}

practices in the range of 11 to $50 \%$ for 6 practices under study (covering water containers, cleaning water containers regularly, treating water in water containers, not storing water, cutting down vegetation around the home, and disposing of old tyres) [8]. One recent qualitative study had identified the barriers to sustained self-prevention which include lack of self-efficacy, lack of perceived benefit, low perceived susceptibility, and unsure perceived susceptibility [9] while others had reported the barriers as misconceptions about dengue from outdated educational materials, "invisibility" of dengue compared with chronic diseases, and lack of acceptance of responsibility for dengue prevention [10]. We suggest to further study the community living in dengue outbreak areas on the barriers for the low frequency of reported larval control practices.

Interestingly, we found only two factors that are independently associated with good larval control practice which 
TABLE 3: Factors associated with level of larval control practice from simple logistic regression analyses.

\begin{tabular}{|c|c|c|c|c|}
\hline Factors & $\begin{array}{c}\text { Crude OR } \\
\text { 95\% C.I. }\end{array}$ & Wald & $\mathrm{df}$ & Sig. \\
\hline Age (years) & $1.01(0.99,1.03)$ & 1.29 & 1 & 0.26 \\
\hline Monthly household income (RM) & $1.00(1.00,1.00)$ & 0.33 & 1 & 0.56 \\
\hline Number of people living in a household & $1.03(0.91,1.17)$ & 0.23 & 1 & 0.63 \\
\hline \multicolumn{5}{|l|}{ Sex } \\
\hline Female & REF & & & \\
\hline Male & $1.24(0.78,1.99)$ & 0.83 & 1 & 0.36 \\
\hline \multicolumn{5}{|l|}{ Highest education level } \\
\hline No formal and primary & REF & & & \\
\hline Secondary and tertiary education & $0.74(0.37,1.47)$ & 0.75 & 1 & 0.39 \\
\hline \multicolumn{5}{|l|}{ Employment status } \\
\hline Employed & $\mathrm{REF}$ & & & \\
\hline Unemployed and housewife & $1.73(1.05,2.84)$ & 4.58 & 1 & 0.03 \\
\hline Student & $0.962(0.43,2.15)$ & 0.01 & 1 & 0.92 \\
\hline Pensioner & $1.67(0.27,10.30)$ & 0.30 & 1 & 0.58 \\
\hline \multicolumn{5}{|l|}{ Citizenship } \\
\hline Malaysian & REF & & & \\
\hline Non-Malaysian & $1.77(0.58,5.39)$ & 0.99 & 1 & 0.32 \\
\hline \multicolumn{5}{|l|}{ Ethnic group } \\
\hline Non-Malay & REF & & & \\
\hline Malay & $0.97(0.54,1.72)$ & 0.01 & 1 & 0.91 \\
\hline \multicolumn{5}{|l|}{ Marital status } \\
\hline Still married & REF & & & \\
\hline Single/divorced/separated & $0.72(0.42,1.23)$ & 1.46 & 1 & 0.23 \\
\hline Knowledge on Aedes mosquitoes & $1.27(1.04,1.55)$ & 5.33 & 1 & 0.02 \\
\hline Knowledge on dengue transmission & $1.04(0.92,1.17)$ & 0.37 & 1 & 0.55 \\
\hline Knowledge of dengue symptoms & $1.06(1.00,1.13)$ & 4.01 & 1 & 0.04 \\
\hline Knowledge on personal preventive measures & $1.18(1.00,1.40)$ & 3.93 & 1 & 0.05 \\
\hline Attitude towards personal preventive measures & $1.08(1.03,1.14)$ & 9.59 & 1 & 0.002 \\
\hline \multicolumn{5}{|l|}{ Risk perception } \\
\hline Low risk & REF & & & \\
\hline Neutral & $0.87(0.44,1.73)$ & 0.16 & 1 & 0.69 \\
\hline Moderate and high risk & $0.92(0.54,1.58)$ & 0.09 & 1 & 0.76 \\
\hline \multicolumn{5}{|l|}{ Ever diagnosed as having dengue infection } \\
\hline No & REF & & & \\
\hline Yes & $1.23(0.56,2.67)$ & 0.26 & 1 & 0.61 \\
\hline \multicolumn{5}{|l|}{ Join the campaign } \\
\hline Never & REF & & & \\
\hline Few and sometimes & $1.51(0.87,2.62)$ & 2.13 & 1 & 0.15 \\
\hline Most of the time and always & $4.09(2.12,7.91)$ & 17.55 & 1 & 0.00 \\
\hline
\end{tabular}

TABLE 4: Factors associated with level of larval control practice in a community in a dengue outbreak prone area.

\begin{tabular}{|c|c|c|c|c|c|}
\hline & $\begin{array}{c}\text { Crude OR }{ }^{\mathrm{a}} \\
(95 \% \mathrm{CI})\end{array}$ & $\begin{array}{c}\text { Adjusted OR } \\
(95 \% \mathrm{CI})\end{array}$ & Wald statistics & df & $P$ value \\
\hline $\begin{array}{l}\text { Attitude towards personal } \\
\text { preventive measures }\end{array}$ & $1.08(1.03,1.14)$ & $1.08(1.02,1.14)$ & 8.24 & 1 & 0.004 \\
\hline \multicolumn{6}{|l|}{ Join the campaign } \\
\hline Never & 1.00 & 1.00 & 16.24 & 2 & 0.000 \\
\hline Few and sometimes & $1.51(0.87,2.62)$ & $1.39(0.79,2.43)$ & 1.32 & 1 & 0.25 \\
\hline Most of the time and always & $4.09(2.12,7.91)$ & $3.83(1.96,7.50)$ & 15.43 & 1 & 0.000 \\
\hline
\end{tabular}

${ }^{\mathrm{a}}$ Simple logistic regression, ${ }^{\mathrm{b}}$ multiple logistic regression.

The model reasonably fits well. Model assumptions are met. There are no interaction and multicolinearity problems. 
are good attitude towards preventive measures (adjusted OR $1.08,95 \%$ CI $1.03,1.14$ ) and frequent self-reporting of joining antidengue campaigns held in the community (adjusted OR 3.83 , 95\% CI 1.96, 7.50). Other sociodemographic factors such as age, sex, educational level, and household income were not significantly associated with larval control practices in this particular community, although some studies have shown the associations of these factors with the practices $[11,12]$. The possible explanation was the almost homogenous sociodemographic characteristics in our studied community which result in the insignificance associations.

Studies correlating knowledge and practices on dengue prevention have shown inconsistent results. In our study, the levels of knowledge regarding Aedes mosquitoes, dengue transmission, symptoms, and the prevention practices were not significantly associated with the frequency of practices of larval control. Although many studies and theoretically good practice are related to the good knowledge level [11, $13,14]$, some studies did show that good knowledge level does not usually correlate with practice [15-19]. We concur with Phuanukoonnon et al. [20] that, during an outbreak, information received through health education activities can raise awareness of dengue infection but is probably insufficient to sustain larval control practices. They identified several barriers which include insufficient control agents and incompatibility of control practices with people's beliefs.

More than one-third (37.0\%) of our respondents never attend antidengue health campaign held in the community. The proportion is slightly less than one study (43.3\%) in Penang regarding never attending any health promotion campaign [21]. We did not study the barriers for those not attending. However, we found that one very important factor is that in order for the community living in a dengue outbreak prone area to change behavior to a high satisfactory level of larval control practices, they need to participate in antidengue campaign held in the neighborhood. This also stressed on the importance of such campaign. Unfortunately, the implementation of antidengue campaign does pose many challenges such as its cost benefits and community mobilization. Therefore, public health authorities should consider the local community priorities in designing antidengue campaign in their area to encourage more participation. Ways to attract people to attend the antidengue campaign should be plotted and applied especially to the high risk area for dengue outbreak.

We identify the limitations of our results that have been obtained from a cross-sectional design where the outcome (larval control practices) and the independent factors were studied at one point of time and thus the temporal effect could be challenged. However, we are very careful in using the term as associations and not risk factors or predisposing factors. We also subjected our data to multiple logistic regression analysis in order to reduce the effect of confounders in our result. Currently, there are no standardized (or validated) questions to assess knowledge, attitude, and practices (KAP) for Aedes control and dengue infection, and this is evidenced from many inconsistencies in the findings of relating practices with the knowledge and attitude as discussed above. We tried to reduce this limitation by pilot-testing the questions earlier and also checked with a content expert before conducting the study.

We recommend extending this study to involve both dengue and nondengue outbreak prone areas and subjecting the communities to intervention packages. It would include the development of educational activities with specific messages with the intention to increase good attitudes and ensure behavior change regarding larval control practices. To measure the outcome more objectively, entomologist should be involved in the study to quantitate vector density.

\section{Conclusion}

Larval control practices are among the required behaviors in order to control dengue infection, especially in dengue risk areas. Our study showed that having a good attitude towards dengue prevention measures and frequent participation in antidengue campaigns are associated with frequent larval control practices in this particular area.

\section{Conflict of Interests}

The authors declare that there is no conflict of interests regarding the publication of this paper.

\section{Acknowledgments}

This study was funded by the Research Intensive Fund, Universiti Teknologi MARA (UiTM), Code no. 600-RMI/DANA 5/3/RIF (307/2012). The authors would also like to thank Year 4 medical students $(2012 / 13)$ for their contribution in collecting the data in this study.

\section{References}

[1] WHO, "Dengue and severe dengue," Fact Sheet 117, WHO, Geneva, Switzerland, 2013.

[2] M. S. Chang, E. M. Christophel, D. Gopinath et al., "Challenges and future perspective for dengue vector control in the Western Pacific Region," Western Pacific Surveillance and Response Journal, vol. 2, no. 2, pp. 9-16, 2011.

[3] S. A. Abubakar and N. Shafee, "Outlook of dengue in Malaysia: a century later," The Malaysian Journal of Pathology, vol. 24, no. 1, pp. 23-27, 2002.

[4] P. Division, Ed., Health Facts 2014, Health Informatics Centre, Ministry of Health, Kuala Lumpur, Malysia, 2014.

[5] K. Bahagian Kawalan Penyakit, "Pelan Strategik Pencegahan dan Kawalan Denggi 2009-2013 Kementerian Kesihatan Malaysia," 2009.

[6] W. Daniel, Biostatistics: A Foundation for Analysis in the Health Sciences, John Wiley \& Sons, New York, NY, USA, 7th edition, 1999.

[7] L. Naing, T. Winn, and B. N. Rusli, "Practical issues in calculating the sample size for prevalence studies," Archives of Orofacial Sciences, vol. 1, pp. 9-14, 2006.

[8] M. Mayxay, W. Cui, S. Thammavong et al., "Dengue in periurban Pak-Ngum district, Vientiane capital of Laos: a community survey on knowledge, attitudes and practices," BMC Public Health, vol. 13, no. 1, article 434, 2013. 
[9] L. P. Wong and S. AbuBakar, "Health beliefs and practices related to dengue fever: a focus group study," PLoS Neglected Tropical Diseases, vol. 7, no. 7, Article ID e2310, 2013.

[10] C. L. Pérez-Guerra, E. Zielinski-Gutierrez, D. Vargas-Torres, and G. G. Clark, "Community beliefs and practices about dengue in Puerto Rico," Revista Panamericana de Salud Publica, vol. 25, no. 3, pp. 218-226, 2009.

[11] S. A. Al-Dubai, K. Ganasegeran, M. R. Alwan, M. A. Alshagga, and R. Saif-Ali, "Factors affecting dengue fever knowledge, attitudes and practices among selected urban, semi-urban and rural communities in Malaysia," Southeast Asian Journal of Tropical Medicine and Public Health, vol. 44, no. 1, pp. 37-49, 2013.

[12] M. Syed, T. Saleem, U.-R. Syeda et al., "Knowledge, attitudes and practices regarding dengue fever among adults of high and low socioeconomic groups," Journal of the Pakistan Medical Association, vol. 60, no. 3, pp. 243-247, 2010.

[13] M. Castro, L. Sańchez, D. Peŕez, C. Sebrango, Z. Shkedy, and P. van der Stuyft, "The relationship between economic status, knowledge on dengue, risk perceptions and practices," PLoS ONE, vol. 8, no. 12, Article ID e81875, 2013.

[14] C. Naing, W. Y. Ren, C. Y. Man et al., "Awareness of dengue and practice of dengue control among the semi-urban community: a cross sectional survey," Journal of Community Health, vol. 36, no. 6, pp. 1044-1049, 2011.

[15] U. D. Ayyamani, G. C. Ying, and O. G. San, "A knowledge attitude and practice (KAP) study on dengue/dengue haemorrhagic fever and the Aedes mosquitoes," The Medical Journal of Malaysia, vol. 41, no. 2, pp. 108-115, 1986.

[16] N. Dégallier, P. de Tarso Ribeiro Vilarinhos, M. S. Laurentino de Carvalho, M. Britto Knox, and J. R. Jorge Caetano, "People’s knowledge and practice about dengue, its vectors, and control means in Brasilia (DF), Brazil: its relevance with entomological factors," Journal of the American Mosquito Control Association, vol. 16, no. 2, pp. 114-123, 2000.

[17] F. Hairi, C. H. S. Ong, A. Suhaimi et al., "A knowledge, attitude and practices (KAP) study on dengue among selected rural communities in the Kuala Kangsar district," Asia-Pacific Journal of Public Health, vol. 15, no. 1, pp. 37-43, 2003.

[18] F. Shuaib, D. Todd, D. Campbell-Stennett, J. Ehiri, and P. E. Jolly, "Knowledge, attitudes and practices regarding dengue infection in Westmoreland, Jamaica," The West Indian Medical Journal, vol. 59, no. 2, pp. 139-146, 2010.

[19] S. Thakolwiboon, N. Benjatikul, K. Sathianvichitr et al., "Factors associated with dengue prevention and control in two villages in a central thai province: a retrospective review," Journal of the Medical Association of Thailand, vol. 96, no. 8, pp. 984-991, 2013.

[20] S. Phuanukoonnon, M. Brough, and J. H. Bryan, "Folk knowledge about dengue mosquitoes and contributions of health belief model in dengue control promotion in Northeast Thailand," Acta Tropica, vol. 99, no. 1, pp. 6-14, 2006.

[21] M. A. Hassali, F. Saleem, A. A. Shafie et al., "Perception towards health promotion activities: findings from a community survey in the state of Penang, Malaysia," Malaysian Journal of Public Health Medicine, vol. 12, no. 2, pp. 6-14, 2012. 


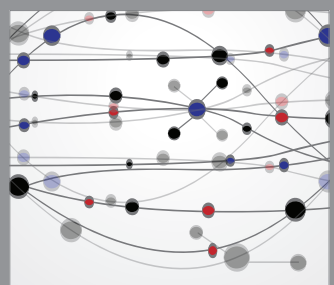

The Scientific World Journal
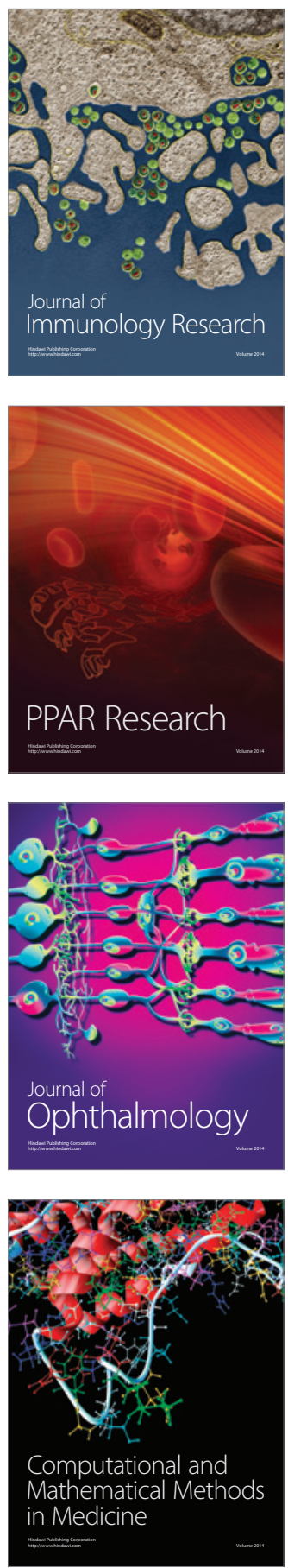

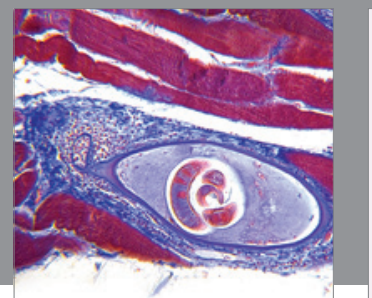

Gastroenterology

Research and Practice
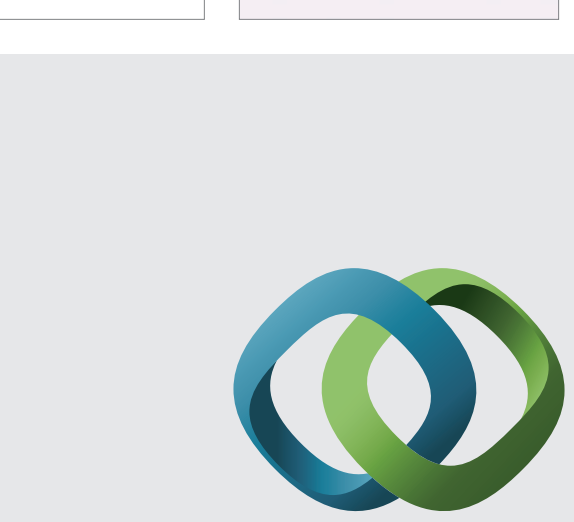

\section{Hindawi}

Submit your manuscripts at

http://www.hindawi.com
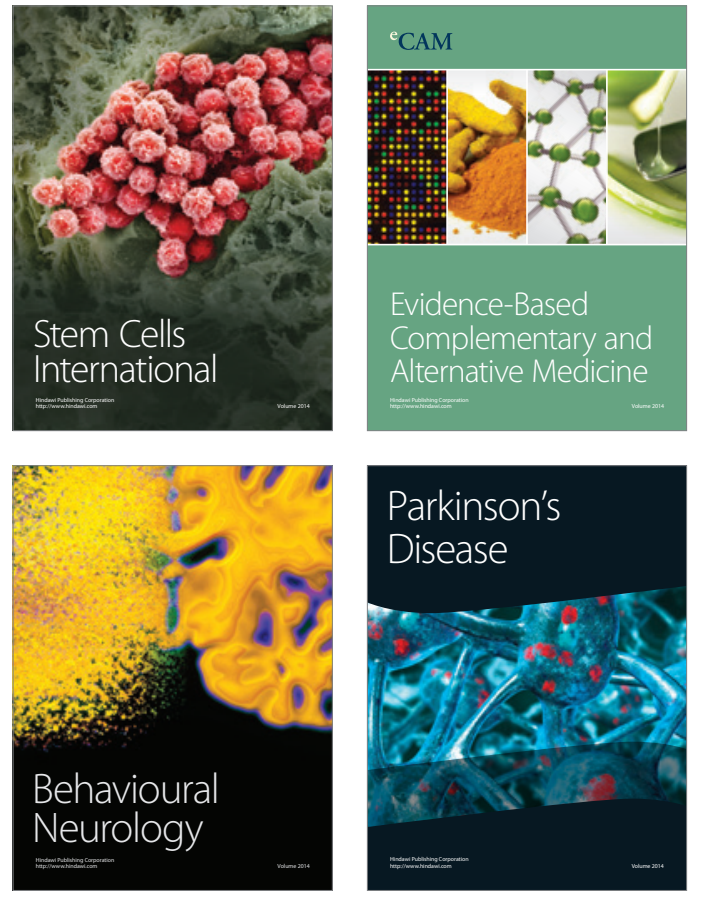
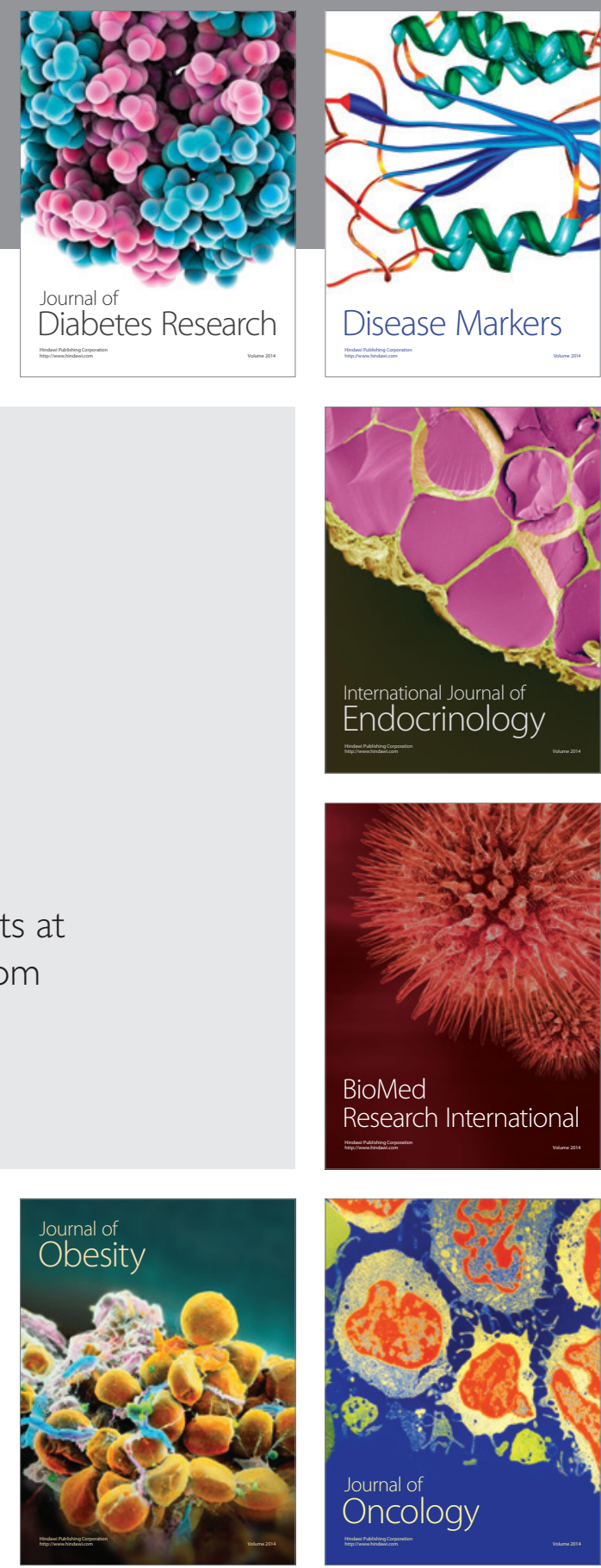

Disease Markers
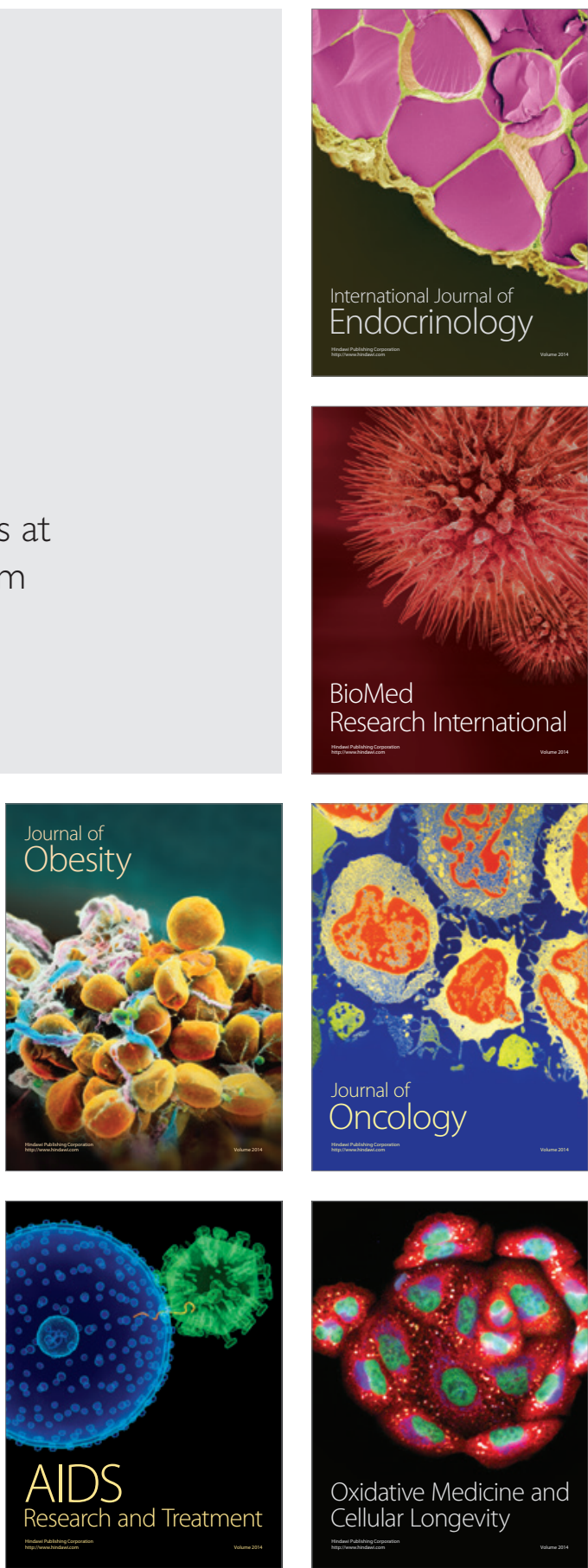